\title{
SURVIVAL IN BASIC LIFE SUPPORT VERSUS ADVANCED LIFE SUPPORT: AN EXPERIMENTAL STUDY
}

\author{
Fontanals J ${ }^{1}$, Caballero A. ${ }^{1}$, Magaldi M. ${ }^{1}$,Bobi J. ${ }^{2}$, Benet P. ${ }^{1}$, Rivera L. ${ }^{1}$ \\ 1.Anaesthesia and Critical Care Department, Hospital Clínic de Barcelona, Spain. \\ 2. Department of Cardiology IDIBAPS, Hospital Clínic de Barcelona, Spain.
}

\section{PURPOSE OF STUDY:}

Performing high-quality bystander cardiopulmonary resuscitation (CPR) improves the clinical outcomes of victims with sudden cardiac arrest (CA). Currently, there are no studies comparing the survival in Basic Life Support (BLS) exclusively versus Advanced Life Support (ALS). The aim of our study is to evaluate the influence of drugs and defibrillation on immiediate survival after cardiac arrest.

\section{METHODS:}

Thirty three Landrace $x$ Large-White pigs underwent $C A$ by ventricular fibrillation, only BLS $(n=10)$ and $\operatorname{ALS}(n=23)$ was initiated after 5 minutes of $C A$ with mechanical chest compressions (LUCAS) and mechanical ventilation. ECG, mean invasive arterial pressure (MAP) and end tidal $\mathrm{CO} 2$ were measured before $C A$ and every two minutes during resuscitation until 16 minutes post-CA. Data were analysed with SPSS statistical software v24.

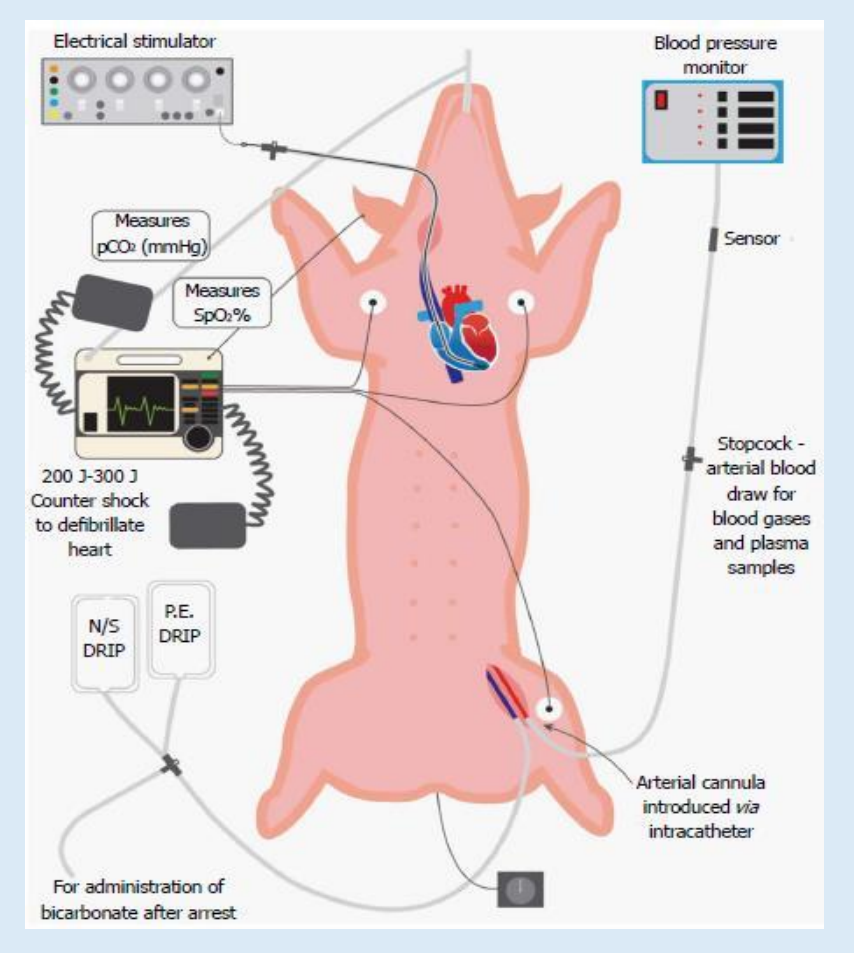

\begin{tabular}{|c|c|c|c|c|c|c|c|c|} 
& $\begin{array}{c}02 \\
\mathrm{~min}\end{array}$ & $\begin{array}{c}04 \\
\mathrm{~min}\end{array}$ & $\begin{array}{c}06 \\
\mathrm{~min}\end{array}$ & $\begin{array}{c}08 \\
\mathrm{~min}\end{array}$ & $\begin{array}{c}10 \\
\mathrm{~min}\end{array}$ & $\begin{array}{c}12 \\
\mathrm{~min}\end{array}$ & $\begin{array}{c}14 \\
\mathrm{~min}\end{array}$ & $\begin{array}{c}16 \\
\mathrm{~min}\end{array}$ \\
\hline MAP (BLS) & $100 \%$ & $\mathbf{9 2 , 9 5} \%$ & $\mathbf{8 8 , 5 6} \%$ & $\mathbf{8 2 , 6 7} \%$ & $\mathbf{7 2 , 9 1} \%$ & $\mathbf{7 0 , 4 5} \%$ & $\mathbf{6 8 , 9 7} \%$ & $\mathbf{6 0 , 5 6} \%$ \\
\hline MAP (ALS) & $100 \%$ & $\mathbf{1 0 6 , 1 4} \%$ & $\mathbf{1 0 4 , 7 0} \% \mathbf{1 1 1 , 0 5} \%$ & $\mathbf{8 9 , 2 4} \%$ & $\mathbf{1 1 6 , 9 5} \%$ & $\mathbf{8 0} \%$ & $\mathbf{7 4 , 2 3} \%$ \\
\hline
\end{tabular}

\section{RESULTS:}

In the ALS group twenty animals (87\%) achieved a return of spontaneous circulation after 16 minutes of maneuvers. In contrast, 0 animals $(0 \%)$ survived in the BLS group. Regarding the hemodynamic monitoring, a decrease in MAP of $39.44 \%$ was observed in the BLS group compared to a reduction of $25.77 \%$ in the ALS group, being these differences statistically significant $(p<0.05)$.

\section{CONCLUSIONS:}

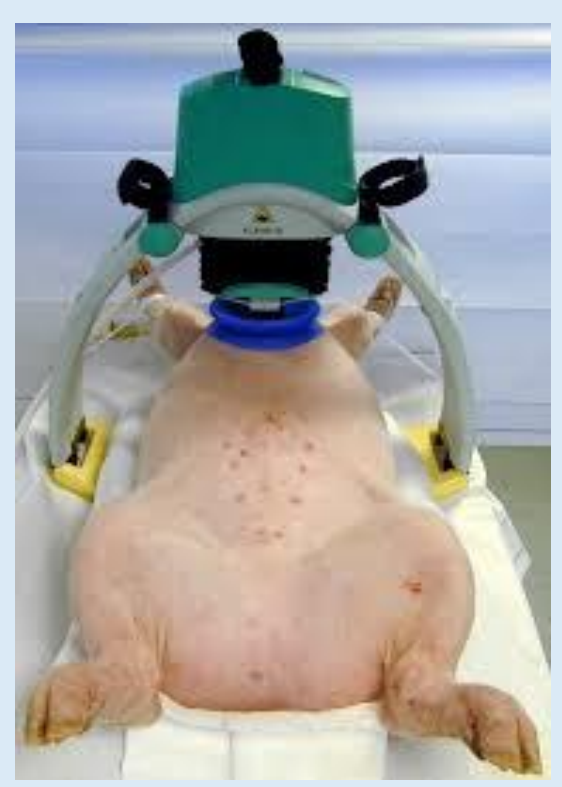

The performance of high quality BLS allows correct maintenance of perfusion and oxygenation of the organs during CA, but only BLS manouvres lead to a very low survival if the medication administration and defibrillation (ALS) are not associated.

Drug administration and defibrillation result in an increase of $13.67 \%$ in MAP compared to the BLS group $(p<0.05)$. This could be one of the reasons that could explain the sharp increase in initial survival after performing ALS versus performing only BLS.

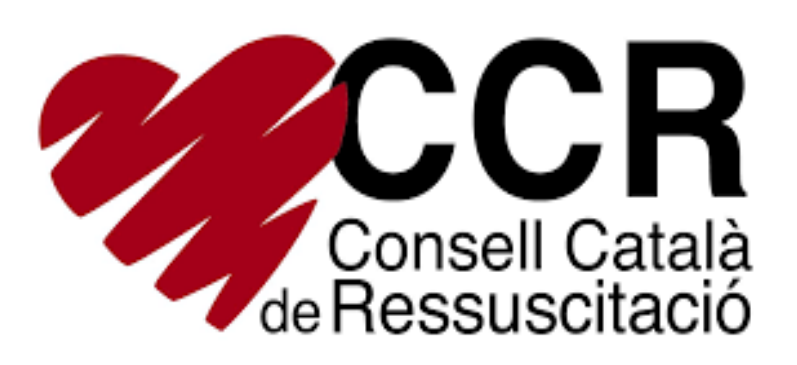

